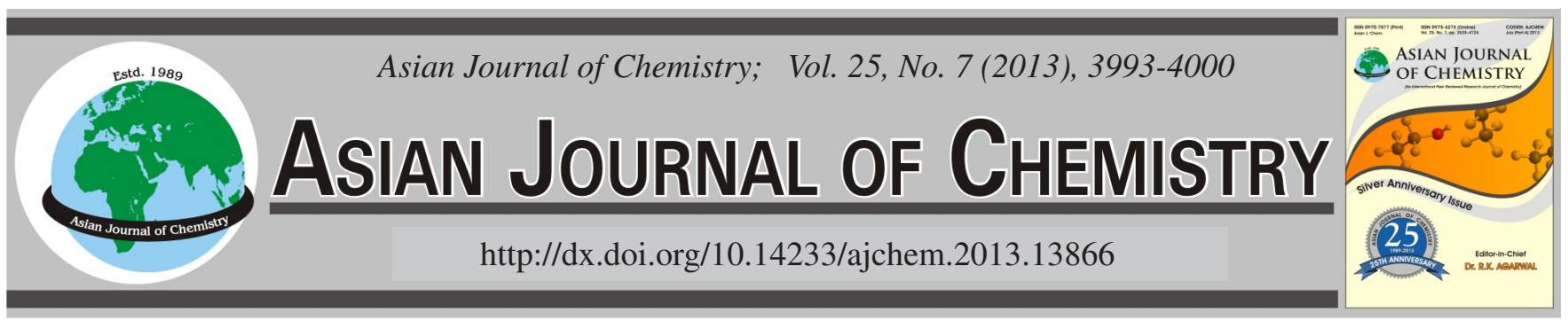

\title{
Delivery of Alzheimer's Drug Donepezil Hydrochloride from Ionically Crosslinked Alginate Microspheres Prepared by Water-in-oil Emulsion Technique: Optimization of Release Conditions
}

\author{
Emine Bulut ${ }^{1}$ and Oya SANLI,**
}

${ }^{1}$ Department of Chemistry, Faculty of Arts and Science, Afyon Kocatepe University, 03200 Afyonkarahisar, Turkey

${ }^{2}$ Department of Chemistry, Science Faculty, Gazi University, 06500 Ankara, Turkey

*Corresponding author: Fax: +90 312 2122279; e-mail: osanli@gazi.edu.tr

(Received: 9 April 2012;

Accepted: 21 January 2013)

AJC-12738

\begin{abstract}
In the present investigation should be microspheres loaded with donepezil hydrochloride (DP) were prepared by water-in-oil emulsion technique using sodium alginate as a hydrophilic carrier. Microspheres were characterized by Fourier transform infrared spectroscopy (FTIR), differential scanning calorimetry (DSC) and scanning electron microscopy (SEM). Swelling experiments were performed to compute the diffusion coefficients and molecular mass between cross-links of the microspheres. In vitro release studies have been performed in 1.2 and $6.8 \mathrm{pH}$ media. Effect of variables such as cross-linker concentration, time of cross-linking, drug/polymer (d/p) ratio on the release, percentage entrapment efficiency, particle size and swelling capacity were determined. The highest donepezil hydrochloride release percentage was obtained as $99.8 \%$ for the cross-linker concentration of $3 \%(w / v)$, drug/polymer ratio of $1 / 4(\mathrm{w} / \mathrm{w})$ at the end of $4 \mathrm{~h}$ in 6.8 media. The release rates were fitted to an empirical equation to compute the diffusional exponent which indicated non-Fickian transport.
\end{abstract}

Key Words: Donepezil hydrochloride, Microspheres, Controlled release, Drug delivery systems, Water soluble polymers.

\section{INTRODUCTION}

In recent years; biodegradable polymeric materials as drug carriers have received considerable attention ${ }^{1-4}$. Physical combination of polymers with drugs are achieved by encapsulation of drugs in polymeric microspheres, beads, micelles and hydrogel type materials ${ }^{5}$. Drug release from these matrixes is controlled by diffusion of the free drug, or the erosion of the matrixes.

Natural polymers such as chitosan, guargum, sodium alginate are often preferred over synthetic polymers due to their non-toxic, low cost, ease of availability and biodegradability characteristics $^{6,7}$. However, several natural biopolymers, especially the class of polysaccharides, have some inherent disadvantages such as poor mechanical strength, uncontrolled water uptake and microbial contamination ${ }^{8}$. Sodium alginate (NaAlg), a water-soluble salt of alginic acid is a natural polysaccharide obtained from brown algae's. It composed of $\beta$-D-mannuronic acid $(M)$ and $\alpha$-L-guluronic acid $(G)$ residues in varying proportions and arrangements. Alginate matrix is formed by cross-linking the guluronic acid units with divalent cations such as $\mathrm{Ca}^{2+}$. However, $\mathrm{Ca}^{2+}$ is preferred as it selectively bind the guluronic acid units to form an egg-box model ${ }^{9-15}$.

Sanli et $a l .{ }^{4}$ we have prepared PVP/NaAlg blend microspheres containing diltiazem hydrochloride to achieve a controlled drug release profile suitable for oral administration. We have reported that diltiazem hydrochloride release from the microspheres increased with both PVP/NaAlg ratio and drug/poymer ratio whereas it decreased with the increase of crosslinker concentration, exposure time to $\mathrm{CaCl}_{2}$ solution and molecular weight of PVP. Lemoine et al. ${ }^{12}$ investigated the controlled release of bovine serum albumin from alginate microspheres. They have found that the release of bovine serum albumin from alginate microspheres was quite faster particularly in phosphate buffered saline solution than in water. They reported that it was possible to delay the release of bovine serum albumin, particularly by coating the alginate microspheres with poly(L-lysine). Babu et al. ${ }^{16}$ studied the controlled release of nifedipine from polymeric blend microspheres consisting of NaAlg and methylcellulose (MC) using water-in-oil emulsion method. They have found that the nifedipine release from the microspheres increased with the increase in $\mathrm{NaAlg} / \mathrm{MC}$ ratio. Zheng et al. ${ }^{17}$ prepared alginatechitosan-poly(lactic-co-glycolic acid) (PLGA) composite microspheres and reported that this kind of novel composite microspheres may be a promising delivery system for water soluble proteins and peptides. Pepperman and Kuan ${ }^{18}$ investigated the controlled release of alachor from alginate microspheres. They found controlled alachor release rates with the addition of linseed oil. 
TABLE-1

PREPARATION CONDITIONS AND THE RESULTS OF ENTRAPMENT EFFICIENCY (\%), MICROSPHERE YIELD $(\%)$, MICROSPHERE SIZES $(\mu \mathrm{m})$ OF THE DONEPEZIL HYDROCHLORIDE LOADED MICROSPHERES

\begin{tabular}{|c|c|c|c|c|c|c|}
\hline Code & $\begin{array}{c}\mathrm{CaCl}_{2} \text { concentration } \\
(\%)(\mathrm{w} / \mathrm{v})\end{array}$ & $\begin{array}{l}\text { Cross linking time } \\
\text { in } \mathrm{CaCl}_{2}(\mathrm{~min})\end{array}$ & $\begin{array}{l}\text { Drug/polymer ratio } \\
\text { (w/w) }\end{array}$ & $\begin{array}{c}\text { Entrapment } \\
\text { efficiency }(\%)\end{array}$ & $\begin{array}{c}\text { Microsphere yield } \\
(\%)\end{array}$ & $\begin{array}{c}\text { Microsphere size } \\
(\mu \mathrm{m})\end{array}$ \\
\hline $\mathrm{A}_{1}$ & 3 & 30 & $1 / 4$ & $20.95 \pm 2.36$ & $74.77 \pm 3.08$ & $43.5 \pm 1.8$ \\
\hline $\mathrm{A}_{2}$ & 5 & 30 & $1 / 4$ & $18,91 \pm 0.17$ & $85.20 \pm 0.57$ & $39.5 \pm 0.9$ \\
\hline $\mathrm{A}_{3}$ & 7 & 30 & $1 / 4$ & $9.08 \pm 0.68$ & $91.20 \pm 2.37$ & $36.7 \pm 2.1$ \\
\hline $\mathrm{A}_{4}$ & 5 & 15 & $1 / 4$ & $18.31 \pm 0.97$ & $69.16 \pm 1.41$ & $73.5 \pm 0.7$ \\
\hline $\mathrm{A}_{5}$ & 5 & 60 & $1 / 4$ & $5.87 \pm 1.56$ & $96.20 \pm 5.09$ & $37.5 \pm 1.8$ \\
\hline $\mathrm{A}_{6}$ & 5 & 120 & $1 / 4$ & $5.08 \pm 0.06$ & $87.50 \pm 4.83$ & $35.2 \pm 1.1$ \\
\hline $\mathrm{A}_{7}$ & 5 & 30 & $1 / 2$ & $14.81 \pm 0.75$ & $62.60 \pm 1.41$ & $98.8 \pm 2.9$ \\
\hline $\mathrm{A}_{8}$ & 5 & 30 & $1 / 8$ & $22.22 \pm 0.16$ & $99.35 \pm 0.92$ & $32.5 \pm 0.5$ \\
\hline $\mathrm{A}_{9}$ & 5 & 60 & $1 / 2$ & $7.04 \pm 0.09$ & $65.39 \pm 1.53$ & $61.5 \pm 1.0$ \\
\hline $\mathrm{A}_{10}$ & 5 & 60 & $1 / 8$ & $8.02 \pm 0.75$ & $99.55 \pm 0.64$ & $30.5 \pm 1.3$ \\
\hline
\end{tabular}

Alzheimer's disease is a progressive, neurodegenerative disease characterized by memory loss, language deterioration, impaired visuospatial skills, poor judgment, indifferent attitude, but preserved motor function. Alzheimer's disease usually begins after age 65, however, its onset may occur as early as age 40, appearing first as memory decline and over several years, destroying cognition, personality and ability to function $^{19}$. Donepezil, galantamine and rivastigmine are the three acetylcholinesterase inhibitors (AChEIs) most widely used to treat Alzheimer's disease ${ }^{20}$. The donepezil chemically ( \pm )-2,3-dihydro-5,6-dimethoxy-2-[[1-(phenylmethyl)-4piperidinyl]methyl]- $1 H$-inden-1-one, is an acetylcholineblocking agent, is known to prevent the rapid hydrolysis of acetylcholine in synapses of central and peripheral nervous system and hence a potent drug for Alzheimer's disease $\mathrm{e}^{21-24}$. Donepezil is available currently in the market as once a daily tablet or capsule $(5 \mathrm{mg} \text { or } 10 \mathrm{mg} / \mathrm{day})^{25}$. However, the adverse effects have been still reported due to enhanced cholinergic activity through the gastrointestine ${ }^{26,27}$. For this reason, it is important to control the drug delivery to improve its bioavailability. One way to overcome the gastrointestinal problems is to use encapsulated the donepezil hydrochloride in controlled release systems. However there are limited number of studies in the literature on the encapsulation of donepezil hydrochloride. Park et $a l .^{21}$ intercalated donepezil molecules into simectite clays (laponite XLG, saponite and montmorillonite) and hybrids were coated with Eudragit ${ }^{\circledR}$ E-100 they have reported that the presence of cationic polymer Eudragit ${ }^{\circledR}$ E-100 showed great enhancement in the release rate

Yan et al. ${ }^{28}$ prepared non-bitter donepezil hydrochloride orally disintegrating tablet for enhanced patient compliance by preparing microspheres with different ratios of drug and Eudragit ${ }^{\circledR}$ EPO using spray drying method and reported that EPO-based drug loaded microspheres neither decreased the bioavailability nor delayed the release of donepezil hydrochloride. Zhang et al..$^{25}$ prepared poly(D,L-lactide-co-glycolide) (PLGA) microparticles by an oil-water emulsion solvent evaporation technique and investigated the controlled release of donepezil from microparticles. Donepezil loaded microparticles released the donepezil within 28 days in water, but showed a slow release in phosphate buffer ( $\mathrm{pH}$ : 7.4) solution.

In the present study we have aimed to prepare donepezil hydrochloride encapsulated sodium alginate microspheres suitable for oral administration. The emulsion cross-linking method has been used for the preparation of the microspheres. Sodium alginate microspheres were prepared in various drug/ polymer ratios using calcium chloride as the cross-linking agent. Particle size, microspheres yield, entrapment efficiency, equilibrium swelling degree of the microspheres were examined and donepezil hydrochloride release rates were investigated at two $\mathrm{pH}$ values (1.2 and 6.8). The effects of cross-linker concentration and time, drug-polymer ratio on donepezil release were also searched and discussed.

\section{EXPERIMENTAL}

Sodium alginate with a medium viscosity was purchased from Sigma Chemical (Louis, USA). Donepezil hydrochloride was provided from Sanovel (Turkey) as a gift. Liquid parafin were supplied from Aklar Chemistry (Turkey). Calcium chloride, span $85, n$-hexane, $\mathrm{Na}_{2} \mathrm{HPO}_{4}$ and $\mathrm{NaH}_{2} \mathrm{PO}_{4}$ were all purchased from Merck (Darmstadt, Germany) and were used as received.

Preparation of sodium alginate microspheres: Waterin-oil emulsion technique was utilized for the preparation of microspheres followed by cross-linking with calcium chloride. The homogenous solution of $\mathrm{NaAlg}(2 \%(\mathrm{w} / \mathrm{v})$ in water) containing donepezil hydrochloride in various drug/polymer ratios were prepared and stirred for $12 \mathrm{~h}$ to form homogenous solution. The aqueous phase was emulsified in light liquid parafin in the ratio of 1:5 (v/v) containing $2 \%(\mathrm{w} / \mathrm{v})$ span 85 using a magnetical stirrer (Nuve, Turkey) at $400 \mathrm{rpm}$ for 15, 30, 60 min. Then $3 \%, 5 \%, 7 \%(\mathrm{w} / \mathrm{v})$ calcium chloride was added slowly to this emulsion and stirred to assure efficient crosslinking. Microspheres were collected by filtration, washed with $n$-hexane and then dried completely in an oven (Memmert, Germany) at $40{ }^{\circ} \mathrm{C}$. Unloaded microspheres were prepared in a smilar way without donepezil hydrochloride to determine equilibrium swelling values of the microspheres. Different variables like drug-polymer ratio, concentration of cross-linking agent and time required for cross-linking were considered in the optimization of the formulation of the microspheres. Preparation conditions were displayed in Table-1.

Equilibrium swelling degree study of the microspheres: Equilibrium swelling degree (ESD) of the cross-linked empty microspheres was determined gravimetrically by measuring the extent of their swelling in the solution of $\mathrm{pH}: 1.2$ and distilled water at $37^{\circ} \mathrm{C}$. To ensure complete equilibration, the samples were allowed to swell for $24 \mathrm{~h}$. The excess surfaceadhered liquid drops were removed by blotting and the swollen 


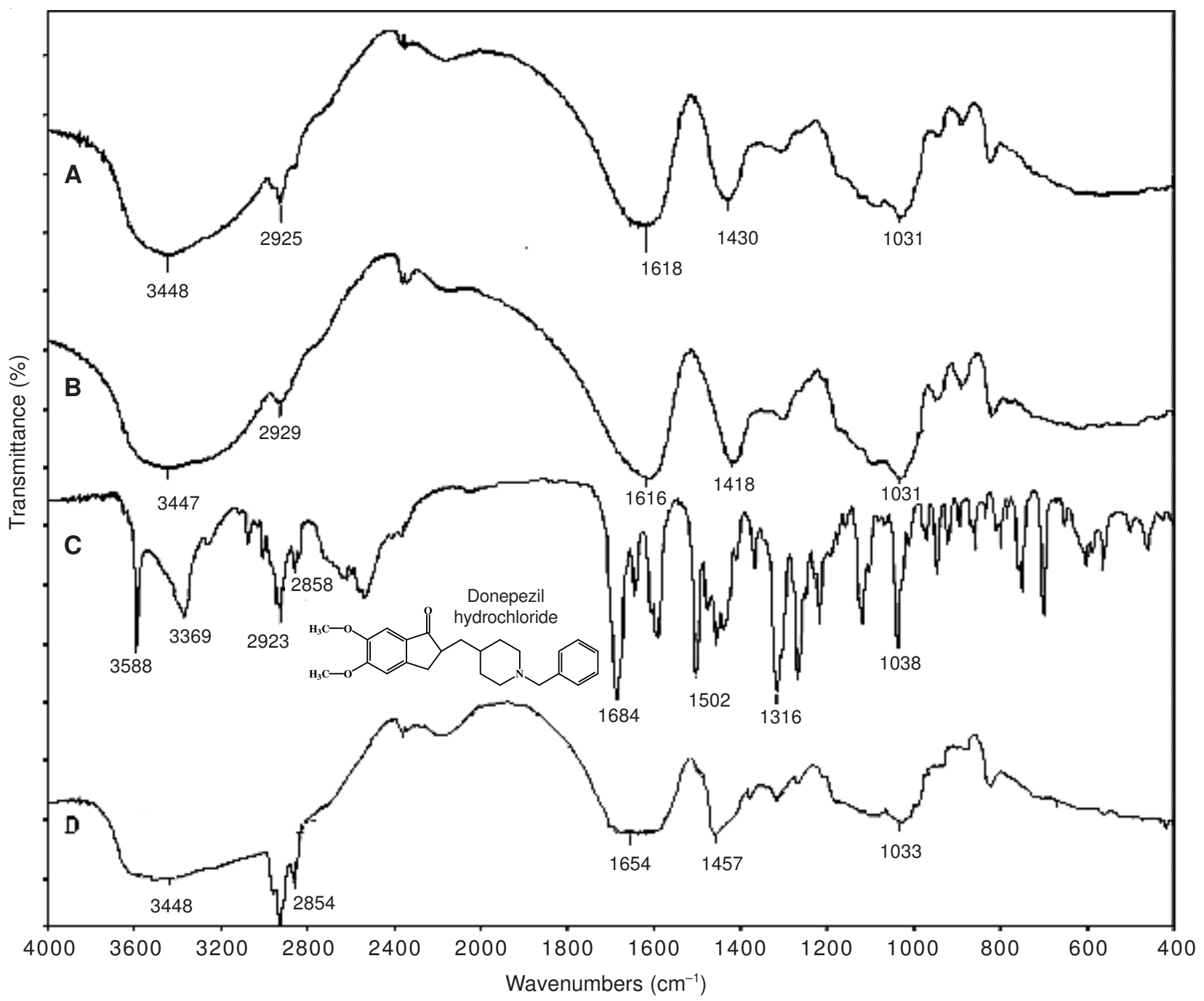

Fig. 1. FTIR results of empty microspheres (A), NaAlg (B), donepezil hydrochloride (C), donepezil hydrochloride-loaded microspheres (D)

microspheres were weighted using electronic balance (Sartorius, Korea) The microspheres were then dried in an oven at $40{ }^{\circ} \mathrm{C}$ until constant weight. The percent ESD was calculated as follows:

Equilibrium swelling degree $(\%):\left(\mathrm{M}_{\mathrm{s}}-\mathrm{M}_{\mathrm{d}}\right) / \mathrm{M}_{\mathrm{d}} \times 100$ where $\mathrm{M}_{\mathrm{s}}$ and $\mathrm{M}_{\mathrm{d}}$ are mass of swollen microspheres and mass of dry microspheres, respectively.

Determination of donepezil hydrochloride content of the microspheres: The known mass of microspheres were crushed in an agate mortar with a pestle and the polymeric powder were refluxed with $250 \mathrm{~mL}$ of distilled water, for $4 \mathrm{~h}$ to ensure the complete extraction of donepezil hydrochloride from the microspheres. After that, the absorbance of the solution containing the extracted amount of donepezil hydrochloride was measured at the wavelength of $270 \mathrm{~nm}$ by a UV spectrophotometer (TU-1880 double Beam UV-VIS) using pure distilled water as a blank. Practical donepezil hydrochloride loading was determined using a calibration curve. The percentage of entrapment efficiency was then calculated as:

Entrapment efficiency $(\%):\left(\frac{\text { Pr actical donepezil loading }}{\text { Theoretical donepezil loading }}\right) \times 100$
Fourier transform infrared measurement (FTIR): FTIR spectra of NaAlg microspheres, NaAlg, donepezil hydrochloride and donepezil hydrochloride loaded NaAlg microspheres were taken in the wavelength region of 4000$400 \mathrm{~cm}^{-1}$ with Perkin-Elmer BX-II (Germany) spectrometer at the ambient temperature and presented in Fig. 1.

Differential scanning calorimetry: The thermal analysis was performed with a differential scanning calorimeter (Shimadzu, Japan). The sample weights ranged from 5 to 8 $\mathrm{mg}$. The samples were heated from $30^{\circ} \mathrm{C}$ to $250^{\circ} \mathrm{C}$ at a heating rate of $10^{\circ} \mathrm{C} / \mathrm{min}$.

Scanning electron microscopic studies (SEM): SEM micrographs were taken with LEO 1430 VP scanning electron microscope (UK) to examine the morphology and surface structure of the microspheres at the required magnification at room temperature. The microspheres were deposited on brass hold and sputtered with a thin coat of gold under vacuum.

Optical microscope: Particle size was measured by using optical microscopy (Olympus CH20BIMF200, Japan).

In vitro drug release: In vitro drug release from the microspheres was studied in $250 \mathrm{~mL}$ conical flasks containing $\mathrm{pH}: 1.2 \mathrm{HCl}$ solution, $\mathrm{pH}: 6.8$ phosphate buffer solution and 

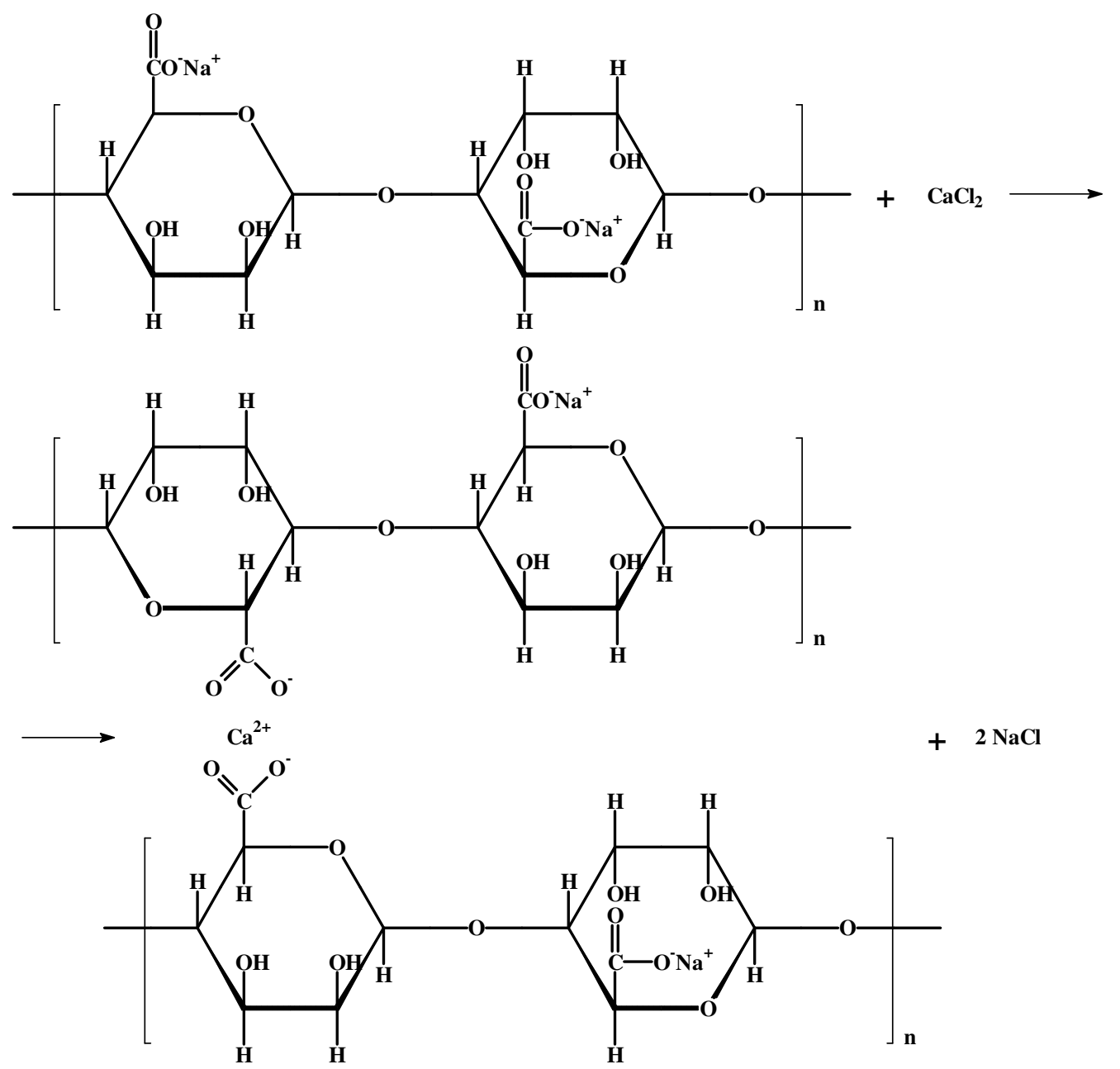

Fig. 2. Possible reaction mechanism of $\mathrm{NaAlg}$ with $\mathrm{CaCl}_{2}$

incubated in a shaking water bath (Medline BS-21, Korea) at $37^{\circ} \mathrm{C}$, with a speed of $100 \mathrm{rpm}$. At $2 \mathrm{~h}$ intervals donepezil hydrochloride release medium was changed with different $\mathrm{pH}$ value solution. Samples are withdrawn at specific time intervals and donepezil content was determined by using UV spectrophotometer at $270 \mathrm{~nm}$. Equal volume of fresh $\mathrm{HCl}$ or phosphate buffer solution was added to the release medium to maintain the constant volume. Experiments were performed in triplicate in order to minimize the variational error. Standard deviations from the average values were calculated.

\section{RESULTS AND DISCUSSION}

FTIR spectra of empty crosslinked NaAlg microsphere and NaAlg are shown in Fig. 1 (A, B). The spectrum of the $\mathrm{NaAlg}$ has shown the bands at arround $3447 \mathrm{~cm}^{-1}$ for $-\mathrm{OH}$ stretching and $2929 \mathrm{~cm}^{-1}$ for aliphatic $\mathrm{C}-\mathrm{H}$ stretching. The bands at 1616, 1418, $1031 \mathrm{~cm}^{-1}$ are due to $\mathrm{COO}^{-}$(asymmetric), $\mathrm{COO}^{-}$(symetric) and C-O-C stretching respectively. The crosslinking process with calcium ion provided a shift of lower intensity of $\mathrm{COO}^{-}$stretching bands at 1616 and $1418 \mathrm{~cm}^{-1}$ to higher wavenumbers $\left(1618 \mathrm{~cm}^{-1} \text { and } 1430 \mathrm{~cm}^{-1}\right)^{4,29,30}$. Possible reaction mechanism for the cross-linking of $\mathrm{NaAlg}$ is presented in Fig. 2.

FTIR spectra of donepezil hydrochloride and drug loaded crosslinked NaAlg microsphere are also shown in Fig. 1 (C, D).
Chemical structure of donepezil hydrochloride is presented in Fig. 1. For donepezil hydrochloride, a sharp peak corresponding to the $\mathrm{C}=\mathrm{O}$ stretching, $\mathrm{C}-\mathrm{N}-\mathrm{C}$ stretching and $\mathrm{C}-\mathrm{H}$ wagging bands were observed at 1684,1502 and $1316 \mathrm{~cm}^{-1}$ respectively. The stretching vibrations of $\mathrm{sp}^{3} \mathrm{C}-\mathrm{H}$ were also seen at 2923 and $2858 \mathrm{~cm}^{-121}$. In the spectrum of donepezil hydrochloride loaded microspheres, the band in $3448 \mathrm{~cm}^{-1}$ is being wider, the band in $1618 \mathrm{~cm}^{-1}$ move to the band in $1654 \mathrm{~cm}^{-1}$ and becomes wider. So polymer and drug have a affection in this point.

Differential scanning calorimetry thermograms of donepezil hydrochloride (A), donepezil hydrochloride-loaded microspheres (B) and empty microspheres (C) are displayed in Fig. 3. Donepezil hydrochloride shows a sharp endothermic peak at $230^{\circ} \mathrm{C}$ due to melting, but in case of donepezil hydrochlorideloaded microspheres, no characteristic peak was observed at $230^{\circ} \mathrm{C}$, suggesting that donepezil hydrochloride is molecularly dispersed in the matrix.

SEM Studies: The shapes of empty microsphere and donepezil hydrochloride-loaded microsphere are shown in Fig. 4. As it is seen from the figure, that empty and donepezil hydrochloride-loaded microsphere are almost spherical in shape and empty microsphere shows smooth surface whereas donepezil hydrochloride loaded microsphere shows roughness in the surface. 


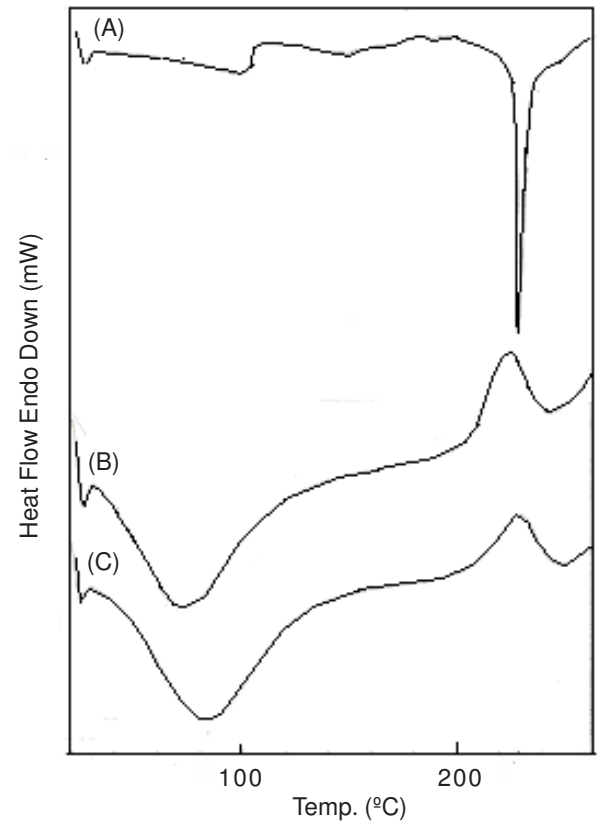

Fig. 3. Differential scanning calorimetry thermograms of donepezil hydrochloride $(\mathrm{A})$, donepezil hydrochloride-loaded $\left(\mathrm{A}_{2}\right)$ microspheres (B), empty $\left(\mathrm{A}_{2,1}\right)$ microspheres $(\mathrm{C})$
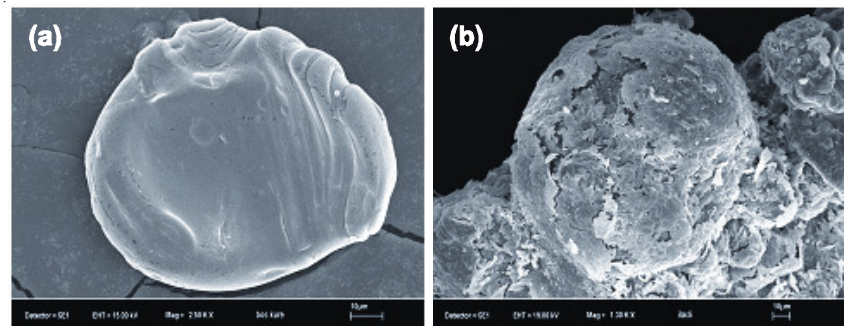

Fig. 4. SEM micrographs of empty NaAlg microsphere $\left(\mathrm{A}_{2,1}\right) \times 2500(\mathrm{~A})$ donepezil hydrochloride loaded NaAlg microsphere $\left(\mathrm{A}_{2}\right) \times 1300$ (B)

Particle size evaluation of microspheres: The results of microsphere diameter, entrapment efficiency (\%) and microsphere yield $(\%)$ were displayed in Table-1. Particle size was measured by optical microscope. As can be seen from the table, the microspheres formed have particle sizes ranging from 30.5 \pm 1.3 to $98.8 \pm 2.9 \mu \mathrm{m}$ in diameter depending on the $\mathrm{d} / \mathrm{p}(\mathrm{w} / \mathrm{w})$ ratio, cross-linker concentration, exposure time to $\mathrm{CaCl}_{2}$. In all of the formulations, with increasing exposure time and $\mathrm{CaCl}_{2}$ concentration, diameter of the microspheres decreases, due to the formation of a more rigid network as a result of increased cross-link density. Babu et al. ${ }^{16}$ have found similar results with sodium alginate methylcellulose blend microspheres.

Effect of concentration of $\mathrm{CaCl}_{2}$ on the donepezil hydrochloride release: Many parameters affect the drug release behaviour of the polymeric microspheres. These include concentration of polymer, physical blending of two polymers, drug crystallinity, drug/polymer ratio, concentration of cross-linking agent, exposure time to cross-linking agent, etc. One of the most effective way to change release rate of microspheres is to change cross-link density of the matrix by employing varying concentrations of the cross-linking agent ${ }^{4}$.

In vitro release of donepezil hydrochloride from crosslinked alginate microspheres was studied in gastric $(2 \mathrm{~h})$ and intestinal $(2 \mathrm{~h}) \mathrm{pH}$ conditions at $37^{\circ} \mathrm{C}$. The effect of $\mathrm{CaCl}_{2}$ concentration on the release rate of donepezil hydrochloride was investigated by varying concentration of $\mathrm{CaCl}_{2}$ solution from $3 \%$ to $7 \%(\mathrm{w} / \mathrm{v})$. The release results from these microspheres are presented in Fig. 5 . $\mathrm{CaCl}_{2}$ concentration of $5 \%(\mathrm{w} / \mathrm{v})$ was preferred in the rest of the study due to the high burst effect at $3 \%(\mathrm{w} / \mathrm{v})$ and low release rate at $7 \%(\mathrm{w} / \mathrm{v})$ $\mathrm{CaCl}_{2}$ concentration. Release results were also supported by swelling measurements given in Table- 2 .

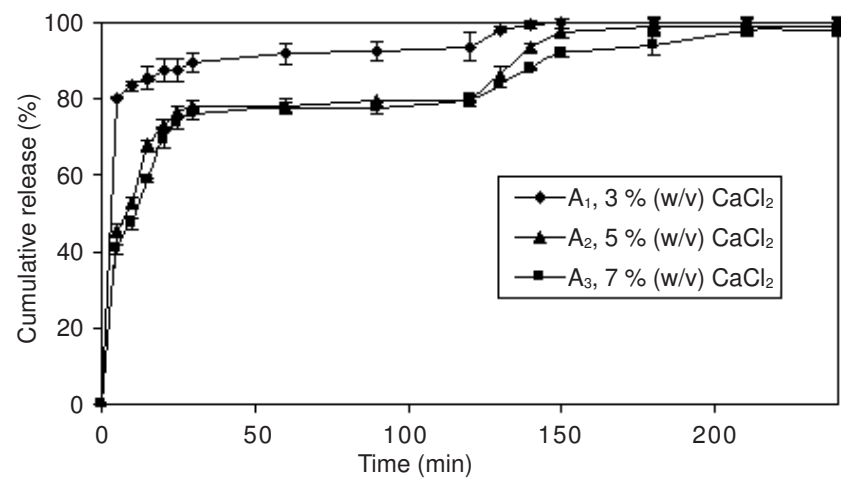

Fig. 5. Effect of $\mathrm{CaCl}_{2}$ concentration on donepezil hydrochloride release. drug/polymer: $1 / 4$, exposure time: $0.5 \mathrm{~h}$

\begin{tabular}{ccccc}
\multicolumn{5}{c}{ TABLE-2 } \\
\multicolumn{5}{c}{$\begin{array}{c}\text { EQUILIBRIUM SWELLING DEGREE } \\
\text { OF EMPTY MICROSPHERES }\end{array}$} \\
\hline Code & $\begin{array}{c}\mathrm{CaCl}_{2} \\
\text { concentration } \\
(\%)\end{array}$ & $\begin{array}{c}\text { Crosslinking } \\
\text { time in } \\
\mathrm{CaCl}_{2}(\mathrm{~min})\end{array}$ & Water & $\mathrm{pH}=1.2$ \\
\hline $\mathrm{A}_{1,1}$ & 3 & 30 & $83.2 \pm 0.76$ & $164.3 \pm 4.67$ \\
$\mathrm{~A}_{2,1}$ & 5 & 30 & $73.7 \pm 2.14$ & $105.5 \pm 1.51$ \\
$\mathrm{~A}_{3,1}$ & 7 & 30 & $45.5 \pm 0.86$ & $94.0 \pm 1.41$ \\
$\mathrm{~A}_{4,1}$ & 5 & 15 & $75.8 \pm 0.85$ & $160.8 \pm 1.38$ \\
$\mathrm{~A}_{5,1}$ & 5 & 60 & $30.0 \pm 2.08$ & $80.0 \pm 2.21$ \\
\hline
\end{tabular}

Similar results were also reported by other workers ${ }^{9,16,31-36}$. Kurkuri et al..$^{31}$ investigated interpenetrating polymeric network (IPN) of poly(vinyl alcohol) and poly(acrylic acid) crosslinked with glutaraldehyde for the in vitro release of diclofenac sodium (DS). They have reported that when the amount of glutaraldehyde increased from 2.5 to $7.5 \mathrm{~mL}$, swelling values decreased. Rastogi et al. ${ }^{9}$ investigated the controlled release of the isoniazid from NaAlg microspheres produced by a modified emulsification method. They found a remarkable delay in the release of isoniazid for NaAlg microspheres with the increase of crosslinker concentration. Sanli and Isiklan ${ }^{34}$ studied controlled release of carbaryl from copper alginate, barium alginate and alginic acid beads. They have reported that carbaryl release gets slower when the microspheres prepared with high crosslinker concentrations. Rokhade et al. ${ }^{36}$ investigated release of the acyclovir from semi-interpenetrating polymer network (IPN) microspheres of chitosan and acrylamide grafted on dextran. They observed that when amount of glutaraldehyde increased from $3 \mathrm{~mL}$ to $9 \mathrm{~mL}$, acyclovir release decreased.

Effect of exposure time to $\mathrm{CaCl}_{2}$ on the donepezil hydrochloride release: Another way to change the crosslink density of the microspheres is to change the exposure time to $\mathrm{CaCl}_{2}$ solution. For this purpose, exposure time to $\mathrm{CaCl}_{2}$ was 
changed from $15 \mathrm{~min}$ to $120 \mathrm{~min}$. The release results are presented in Fig. 6, which clearly indicates that with increasing cross-linking time, the release rate decreases. The maximum donepezil hydrochloride release from the microsphere was found to be $99.6 \%$ at the end of $150 \mathrm{~min}$ for the microspheres prepared with cross-linking time of $15 \mathrm{~min}$.

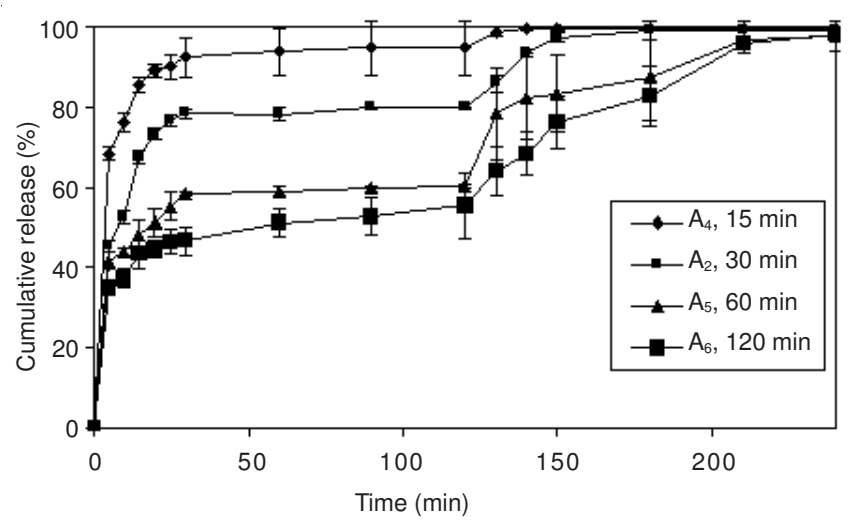

Fig. 6. Effect of exposure time on donepezil hydrochloride release. drug/ polymer: $1 / 4$, concentration of $\mathrm{CaCl}_{2}: 5 \%$

The observed decrease in the cumulative release may be attributed to the fact that increasing exposure time to crosslinker results increase in the cross-link density, which gives rise to a compact network of the polymer. Consequently, the free volume reduces and penetration of water molecules and diffusion of donepezil hydrochloride molecules become difficult. When the cross-linking time is increased the burst effect decreased. So release gets controlled. After that, the effect of the drug/polymer ratio on the release for the crosslinking time of $30 \mathrm{~min}$ and $60 \mathrm{~min}$ were investigated. Effect of cross-linking time on the release of donepezil hydrochloride from microspheres was also supported by swelling measurements. As it is seen from the Table-2, increase in exposure time to $\mathrm{CaCl}_{2}$ decreased swelling percentage. Similar observations were reported in some studies in the literature ${ }^{4,33,37}$. Zhang et $a l .{ }^{37}$ studied the effect of exposure time to crosslinker on the release of 5-fluorouracil from bovine serum albumin microspheres and obtained similar findings.

Effect of the drug/polymer ratio on the donepezil hydrochloride release: To investigate the effect of drug/polymer ratio on donepezil hydrochloride release, drug/polymer ratio was changed from $1 / 8$ to $1 / 2$ for the alginate microspheres cosslinked with $5 \% \mathrm{CaCl}_{2}$ for 0.5 and $1 \mathrm{~h}$ and release results were shown in Figs. 7 and 8.

At the end of $2 \mathrm{~h}$, the release of donepezil hydrochloride from $\mathrm{d} / \mathrm{p}$ ratio of $1 / 2,1 / 4$ and $1 / 8$ microspheres were found to be $90.10,79.75$ and $59.56 \%$ for $0.5 \mathrm{~h}$ of cross-linking time and $72.64,60.23$ and $52.56 \%$ for $1 \mathrm{~h}$ cross-linking time. Similar result was reported by Babu et al. ${ }^{16}$. They have studied carbohydrate polymeric blend microspheres consisting of $\mathrm{NaAlg}$ and methylcellulose for the controlled release of nifedipine and reported that nifedipine release increased with the amount of drug in the matrix.

Entrapment efficiency and yield value evaluation of the microspheres: Percentage of entrapment efficiency and microsphere yield may change depending on the preparation

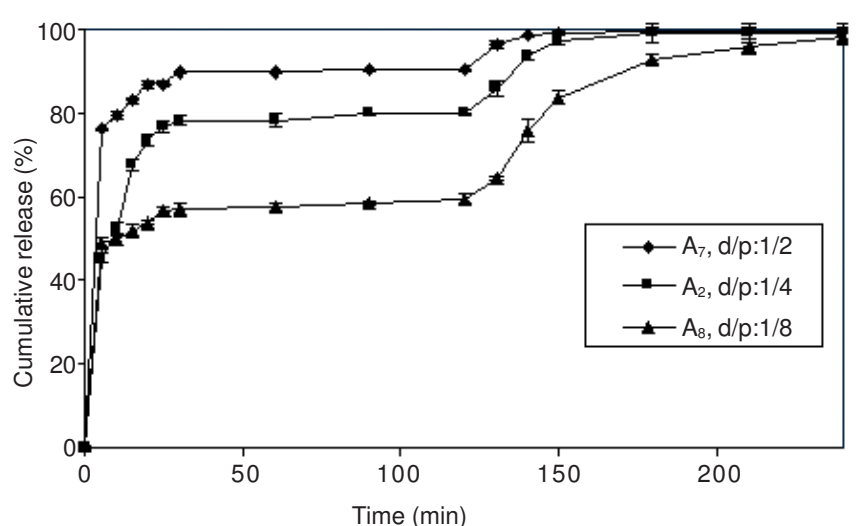

Fig. 7. Effect of drug/polymer ratio on donepezil hydrochloride release. concentration of $\mathrm{CaCl}_{2}: 5 \%$, exposure time to $\mathrm{CaCl}_{2}: 0.5 \mathrm{~h}$

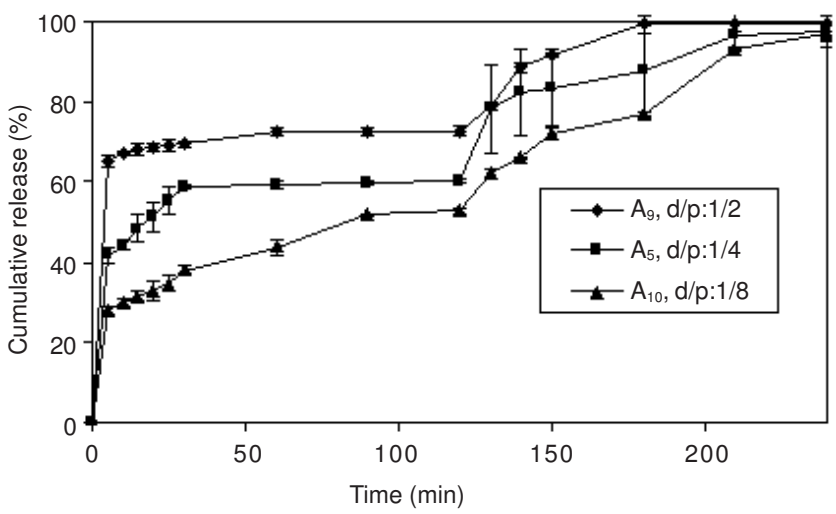

Fig. 8. Effect of drug/polymer ratio on donepezil hydrochloride release. concentration of $\mathrm{CaCl}_{2}: 5 \%$, exposure time to $\mathrm{CaCl}_{2}: 1 \mathrm{~h}$

conditions and the type of matrix material of the microspheres. The results of entrapment efficiecy $(\%)$ and microsphere yield $(\%)$ and microsphere size $(\mu \mathrm{m})$ were shown in Table-1. For the 0.5 and $1 \mathrm{~h}$ crosslinked microspheres, as the drug/polymer ratio increases from $1 / 8$ to $1 / 2$, the entrapment efficiency decreases from 22.22 to $14.81 \%$ and from 8.02 to $7.04 \%$, respectively. This phenomenon may be explained as follows: when drug/polymer ratio increases, NaAlg traps less donepezil hydrochloride and thus entrapment efficiency decreases.

As can also be seen from the Table-1, increase in crosslinker concentration and time decreases the entrapment efficiency. Such a decreasing trend can be attributed to the increase crosslinking density of the microspheres which might have become more rigid structure as a result of reduction in free volume within the polymer matrix; thereby reduces their entrapment efficiencies. Similar results were stated by Isiklan ${ }^{32}$. Isiklan prepared calcium alginate and nickel alginate hydrogel beads for the delivery of insecticide carbaryl and found that entrapment efficiency decreased with the increase in the drug/ polymer ratio and crosslinker concentration. Decreasing trend may also be due to the high aqueous solubility of donepezil hydrochloride resulting in loss of the drug in hardening, washing and filtering processes. Similar results were reported by other workers ${ }^{4,9,35}$. Denkbas et al ${ }^{35}$ prepared scaffolds composed of chitosan containing 5-fluorouracil (5-FU). They have reported that the drug loading was not very high due to high solubility of 5-fluorouracil in water. 
Drug release kinetics: The phenomenon of solvent sorption by a polymeric microsphere depends mechanistically on the diffusion of water molecules into the gel matrix and subsequent relaxation of macromoleculer chains of the bead ${ }^{38}$.

Drug release kinetics was analyzed by plotting cumulative release data versus time and by fitting these data to the exponential equation of the type ${ }^{39}$.

$$
\left(\frac{M_{t}}{M_{\infty}}\right)=k \cdot t^{n}
$$

Here, $\mathbf{M}_{\mathrm{t}}$ is the amount of donepezil hydrochloride released at time $t$ and $M_{\infty}$ is the drug released at equilibrium time; $\mathrm{k}$, a constant characteristic of the drug-polymer system; and $\mathrm{n}$ is an empirical parameter characterizing the release mechanism. Fickian release is defined by an initial $t^{1 / 2}$ time dependence of the fractional release for slabs, cylinders and spheres. Analogously, case-II transport is defined by an initial linear time dependence of the fractional release for all geometries. If $n=0.5$, then drug diffuses and releases from the polymer matrix following a Fickian diffusion. For $\mathrm{n}>0.5$, an anamolous or non-Fickan type drug diffusion occurs. If $n=1$, a completely non-Fickian or case-II release kinetics is operative. The intermediary values ranging between 0.5 and 1.0 are atributed to the anomalous type transport ${ }^{39}$.

The least-squares estimations of the fractional release data along with the estimated corelation coefficient values, $r$, are presented in Table-3. From these data, then $\mathrm{n}$ value ranged betwen $0.334-0.868$, indicating donepezil hydrochloride release from the microspheres display non-Fickian transport.

TABLE-3

D, $\mathrm{k}, \mathrm{n}, \mathrm{r}$ VALUES CALCULATED FROM EQS. (3) AND (4)

\begin{tabular}{cccccl}
\hline Code & $\begin{array}{c}\mathrm{D} \mathrm{x} 10^{12} \\
\left(\mathrm{~cm}^{2} / \mathrm{s}\right)\end{array}$ & $\mathrm{k}\left(\mathrm{min}^{-\mathrm{n}}\right)$ & $\mathrm{n}$ & $\mathrm{r}$ & $\begin{array}{l}\text { Diffusion } \\
\text { mechanism }\end{array}$ \\
\hline $\mathrm{A}_{1}$ & 3.65 & 0.2229 & 0.868 & 0.9965 & Non-Fickian \\
$\mathrm{A}_{2}$ & 2.85 & 0.1411 & 0.658 & 0.9657 & Non-Fickian \\
$\mathrm{A}_{3}$ & 2.31 & 0.1323 & 0.599 & 0.9670 & Non-Fickian \\
$\mathrm{A}_{4}$ & 12.4 & 0.1879 & 0.848 & 0.9991 & Non-Fickian \\
$\mathrm{A}_{5}$ & 1.21 & 0.1623 & 0.405 & 0.9289 & Fickian transport \\
$\mathrm{A}_{6}$ & 0.74 & 0.1461 & 0.367 & 0.9162 & Fickian transport \\
$\mathrm{A}_{7}$ & 19.4 & 0.2114 & 0.868 & 0.9996 & Non-Fickian \\
$\mathrm{A}_{8}$ & 0.84 & 0.1994 & 0.375 & 0.8867 & Fickian transport \\
$\mathrm{A}_{9}$ & 4.37 & 0.1879 & 0.836 & 0.9989 & Non-Fickian \\
$\mathrm{A}_{10}$ & 0.32 & 0.1217 & 0.334 & 0.9349 & Fickian transport \\
\hline
\end{tabular}

Diffusion coefficient (D) can be calculated for water absorption or drug release by microspheres using the equation as follows ${ }^{40}$.

$$
\mathrm{D}=\left(\frac{\mathrm{r} \theta}{6 \mathrm{M}_{\infty}}\right)^{2} \pi
$$

where, $\theta$ is slope of the linear portion of the plot of $\mathrm{M}_{\mathrm{t}} / \mathrm{M}_{\infty} v s$. $t^{1 / 2} . r$ is radius of the dry microspheres and $M_{\infty}$ is the maximum drug release. The data reported in Table- 3 shows the relationship between diffusion coefficient and the exposure time, concentration of $\mathrm{CaCl}_{2}$ and drug/polymer ratio. The diffusion coefficient value decreases from $3.65 \times 10^{-12}$ to $2.31 \times 10^{-12}$ $\mathrm{cm}^{2} / \mathrm{s}$ with increasing $\mathrm{CaCl}_{2}$ concentration. An increase in exposure time to $\mathrm{CaCl}_{2}$ decreases the diffusion coefficient, which is also in agreement with the release results $\left(\mathrm{A}_{4}, \mathrm{~A}_{2}, \mathrm{~A}_{5}, \mathrm{~A}_{6}\right)$. The diffusion coefficient values also increase with increasing drug/polymer (for example $A_{2}, A_{7}, A_{8}$ ). Similar results were reported by many other workers ${ }^{16,30,36,40}$. Rokhade et al. ${ }^{36}$ prepared microspheres of acrylamide grafted on dextran and chitosan by emulsion-cross-linking method. They have reported that when the amount of crosslinker increased, diffusion coefficient values decreased and when the drug/polymer ratio increased, diffusion coefficient values also increased. Rokhade and his group studies supported the donepezil hydrochloride release results.

Determination of molar mass between crosslinks: Release of drug from the polymer matrix is a function of the extent of cross-linking. To understand the extent of crosslinking of the polymer, it is necessary to calculate the molar mass between the crosslinks of the polymer (Mc). Equilibrium swelling is used to determine Mc. We have attempted to calculate the molecular mass (Mc), between cross-links using the Flory-Rehner equation ${ }^{41}$ :

$$
\mathrm{M}_{\mathrm{c}}=\rho_{\mathrm{p}} \mathrm{V}_{\mathrm{s}} \phi^{1 / 3}\left[\ln (1-\phi)+\phi+\chi \phi^{2}\right]^{-1}
$$

The volume fraction, $\phi$, of the swollen polymer was calculated as follows:

$$
\phi=\left[1+\frac{\rho_{\mathrm{p}}}{\rho_{\mathrm{s}}}\left(\frac{\mathrm{M}_{\mathrm{a}}}{\mathrm{M}_{\mathrm{b}}}\right)-\frac{\rho_{\mathrm{p}}}{\rho_{\mathrm{s}}}\right]^{-1}
$$

In the above equations, $\rho_{\mathrm{p}}$ and $\rho_{\mathrm{s}}$ are the densities of polymer and solvent respectively. $\mathrm{M}_{\mathrm{b}}$ and $\mathrm{M}_{\mathrm{a}}$, are the mass of polymer before and after swelling respectively. $\mathrm{V}_{\mathrm{s}}$ is the molar volume of the solvent. The interaction parameter, $\chi$ can be calculated with the Flory- Rehner equation:

$\chi=\left[\phi(1-\phi)^{-1}+\mathrm{N} \ln (1-\phi)+\mathrm{N} \phi\right] \times\left[2 \phi-\phi^{2} \mathrm{~N}-\phi^{2} \mathrm{~T}^{-1}(\mathrm{~d} \phi / \mathrm{dT})^{-1}\right]^{-1}(7)$ where $\mathrm{N}$ is:

$$
\mathrm{N}=\left(\frac{\phi^{2 / 3}}{3}-\frac{2}{3}\right)\left(\phi^{1 / 3}-\frac{2 \phi}{3}\right)^{-1}
$$

and $\mathrm{d} \phi / \mathrm{dt}$ is the slope of the line obtained by plotting the volume fraction $v s$. temperature $(\mathrm{K})$.

The $\mathrm{M}_{\mathrm{c}}$ values were calculated from the equilibrium swelling data at three different temperatures. $\mathbf{M}_{\mathrm{c}}$ values calculated for the donepezil hydrochloride-loaded microspheres are presented in Table-4. The $\mathrm{M}_{\mathrm{c}}$ values increase with increasing temperature and varies in the range from 955 to 2847 . These data indicate that, $\mathrm{M}_{\mathrm{c}}$ values decrease with increasing amount of $\mathrm{CaCl}_{2}$ in the formulation, which supports the donepezil hydrochloride release results. Similar types of results have also been reported elsewhere ${ }^{30,40,42,43}$. Inal et al. ${ }^{30}$ prepared indomethacin containining sodium alginate beads by crosslinking with glutaraldehyde. They reported that $\mathbf{M}_{\mathrm{c}}$ values decrease with increasing amount of glutaraldehyde in the formulation.

\section{Conclusion}

This study which is based on the release of Alzheimer's drug donepezil hydrochloride from the microspheres prepared from sodium alginate by emulsification cross-linking method indicate that release increases with the increase in $d / p$ ratio whereas decreases with the increase of crosslinker concentration and time. The highest donepezil hydrochloride release is found to be $99.8 \%$ for $\mathrm{CaCl}_{2}$ concentration of $3 \%(\mathrm{w} / \mathrm{v})$ and $\mathrm{d} / \mathrm{p}$ ratio of $1 / 4$ at the end of $4 \mathrm{~h}$ in $\mathrm{pH}$ of 6.8 media. Equilibrium swelling degrees and diffusion constants of all 


\begin{tabular}{|c|c|c|c|c|c|}
\hline \multicolumn{6}{|c|}{$\begin{array}{l}\text { TABLE-4 } \\
\text { MOLECULAR MASS BETWEEN CROSSLINKS OF NaAlg } \\
\text { MICROSPHERES WITH DIFFERENT COMPOSITIONS }\end{array}$} \\
\hline $\begin{array}{c}\text { Swelling } \\
\text { temperature }\left({ }^{\circ} \mathrm{C}\right)\end{array}$ & Code & $\mathrm{N}$ & $\phi$ & $\chi$ & $\mathrm{M}_{\mathrm{c}}$ \\
\hline 27 & \multirow[t]{3}{*}{$\mathrm{A}_{1}$} & -1.0357 & 0.3500 & 0.5452 & 2019 \\
\hline 37 & & -1.0373 & 0.3381 & 0.5453 & 2296 \\
\hline 47 & & -1.0406 & 0.3153 & 0.5411 & 2847 \\
\hline 27 & \multirow[t]{3}{*}{$\mathrm{A}_{4}$} & -1.0353 & 0.3390 & 0.5894 & 1837 \\
\hline 37 & & -1.0468 & 0.3758 & 0.5835 & 2184 \\
\hline 47 & & -1.0524 & 0.3667 & 0.5834 & 2430 \\
\hline 27 & \multirow[t]{3}{*}{$\mathrm{A}_{2}$} & -1.0496 & 0.4104 & 0.5862 & 1520 \\
\hline 37 & & -1.0369 & 0.3930 & 0.5819 & 1773 \\
\hline 47 & & -1.0425 & 0.3831 & 0.5816 & 1972 \\
\hline 27 & \multirow[t]{3}{*}{$\mathrm{A}_{5}$} & -0.9792 & 0.5479 & 0.7063 & 955 \\
\hline 37 & & -0.9886 & 0.5109 & 0.6771 & 1148 \\
\hline 47 & & -0.9949 & 0.4905 & 0.6655 & 1316 \\
\hline 27 & \multirow[t]{3}{*}{$\mathrm{A}_{7}$} & -1.0572 & 0.3930 & 0.5769 & 1679 \\
\hline 37 & & -1.0464 & 0.3764 & 0.5734 & 1957 \\
\hline 47 & & -1.0539 & 0.3641 & 0.5722 & 2217 \\
\hline
\end{tabular}

the formulations were found to be in consistence with the release results. The data of molar mass between the crosslinks also indicate that an increase in the concentration of $\mathrm{CaCl}_{2}$, exposure time to $\mathrm{CaCl}_{2}$ means a decrease in $\mathrm{M}_{\mathrm{c}}$ values. From these results, it can be concluded donepezil hydrochloride release from the NaAlg microspheres depends on the preparation conditions and $\mathrm{pH}$ values of the medium.

\section{ACKNOWLEDGEMENTS}

The authors are grateful to the Gazi University Scientific Research Foundation for support of this study.

\section{REFERENCES}

1. Y.J. Fu, S.S. Shyu, F.H. Su and P.C. Yu, Colloid. Surf., 25, 269 (2002).

2. A.R.C. Duarte, M.S. Costa, A.L. Simplicio, M.M. Cardoso and C.M.M. Duarte, Int. J. Pharm., 308, 168 (2006).

3. S. Bozdag, S. Çalis, H.S. Kas, M.T. Ercan, I. Peksoy and A.A. Hincal, J. Microencapsul., 18, 443 (2001).

4. O. Sanli, E. Biçer and N. Isiklan, J. Appl. Polym. Sci., 107, 1973 (2008).

5. Z. Liu and S. Rimmer, J. Control. Rel., 81, 91 (2002).

6. K.S. Soppimath and T.M. Aminabhavi, Eur. J. Pharm. Biopharm., 53, 87 (2002).

7. S.G. Kumbar and T.M. Aminabhavi, J. Appl. Polym. Sci., 89, 2940 (2003).

8. S.G. Kumbar, K.S. Soppimath and T.M. Aminabhavi, J. Appl. Polym. Sci., 87, 1525 (2003)

9. R. Rastogi, Y. Sultana, M. Aqil, A. Ali, S. Kumar, K. Chuttani and A.K. Mishra, Int. J. Pharm., 334, 71 (2007).

10. S. Peretz and O. Cinteza, Colloid. Surf. A., 319, 165 (2008).
11. B. Arica, S. Çalis, H.S. Kas, M.F. Sargon and A.A. Hincal, Int. J. Pharm., 242, 267 (2002).

12. D. Lemoine, F. Wauters, S. Bouchend'homme and V. Preat, Int. J. Pharm., 176, 9 (1998).

13. S. Martins, B. Sarmento, E.B. Souto and D.C. Ferreira, Carbohydr. Polym., 69, 725 (2007).

14. X. Liu, W.S. Heng, Q. Li and L.W. Chan, J. Control. Rel., 116, 35 (2006).

15. I. Rousseau, D.L. Cerf, L. Picton, J.F. Argillier and G. Muller, Eur. Polym. J., 40, 2709 (2004).

16. V.R. Babu, M. Sairam, K.M. Hosamani and T.M. Aminabhavi, Carbohydr. Polym., 69, 241 (2007).

17. C.H. Zheng, J.Q. Gao, Y.P. Zhang and W.Q. Liang, Biochem. Biophys. Res. Commun.., 323, 1321 (2004).

18. A.B. Pepperman and J.C.W. Kuan, J. Control. Rel., 34, 17 (1995).

19. W.H. Liu, J.L. Song, K. Liu, D.F. Chu and Y.X. Li, J. Control. Rel., 107, 417 (2005).

20. C. Christodoulou, P. Melville, W.F. Scherl, W.S. MacAllister, L.E. Elkins and L.B. Krupp, J. Neuro. Sci., 245, 127 (2006).

21. J.K. Park, Y.B. Choy, J.-M. Oh, J.Y. Kim, S.-J. Hwang and J.-H. Choy, Int. J. Pharm., 359, 198 (2008).

22. P. Rocca, E. Cocuzza, L. Marchiaro and F. Bogetto, Prog. NeuroPsychop. Bio. Psych., 26, 369 (2002).

23. J.I. Friedman, D.N. Adler, E. Howanitz, P.D. Harvey, G. Brenner, H. Temporini, L. White, M. Parrella and K.L. Davis, Biol. Psychiatry, 51, 349 (2002).

24. S. Kafkala, S. Matthaiou, P. Alexaki, M. Abatzis, A. Bartzeliotis and M. Katsiabani, J. Chromatogr. A, 1189, 392 (2008).

25. P. Zhang, L. Chen, W. Gu, Z. Xu, Y. Gao and Y. Li, Biomaterials, 28, 1882 (2007).

26. C.H.T.P. Da Silva, V.L. Campo, I. Carvalho and C.A. Taft, J. Mol. Graph. Model., 25, 169 (2006).

27. J.-M. Contreas, I. Parrot, W. Sippl, Y.M. Rival and G.G. Wermuth, J. Med. Chem., 44, 2707 (2001).

28. Y.-D. Yan, J.S. Woo, J.H. Kang, C.S. Yong and H.G. Choi, Biol. Pharm. Bull., 33, 1364 (2010).

29. Z. Dong, Q. Wang and Y. Du, J. Membr. Sci., 280, 37 (2006).

30. M. Inal, M. Yigitoglu and N. Isiklan, e-Polymers, 017 (2008).

31. M.D. Kurkuri and T.M. Aminabhavi, J. Control. Rel., 96, 9 (2004).

32. N. Isiklan, J. Appl. Polym. Sci., 105, 718 (2007).

33. O. Sanli, N. Ay and N. Isiklan, Eur. J. Pharm. Biopharm., 65, 204 (2007).

34. O. Sanli and N. Isiklan, J. Appl. Polym. Sci., 102, 4245 (2006).

35. E.B. Denkbas, M. Seyyal and E. Piskin, J. Membr. Sci., 172, 33 (2000).

36. A.P. Rokhade, S.A. Patil and T.M. Aminabhavi, Carbohydr. Polym., 67, 605 (2007).

37. C. Zhang, Y. Cheng, G. Qu, X. Wu, Y. Ding, Z. Cheng, L. Yu and Q. Ping, Carbohydr. Polym., 72, 390 (2008).

38. A.K. Bajpai and M. Sharma, J. Macromol. Sci.-Pure Appl. Chem., 42, 663 (2005)

39. P. Ritger and N.A. Peppas, J. Control. Rel., 5, 37 (1987).

40. S.A. Agnihotri and T.M. Aminabhavi, Int. J. Pharm., 324, 103 (2006).

41. P.J. Flory, Principles of Polymer Chemistry, Cornell University, Ithaca, NY (1953).

42. O. Sanli and E. Kondolot Solak, J. Appl. Polym. Sci., 112, 2057 (2009).

43. A.R. Kulkarni, K.S. Soppimath, T.M. Aminabhavi and W.E. Rudzinski, Eur. J. Pharm. Biopharm., 51, 127 (2001). 